\section{Endoscopic ultrasound-guided transgastric drainage for omental bursa abscess complicating appendicitis with diffuse peritonitis}

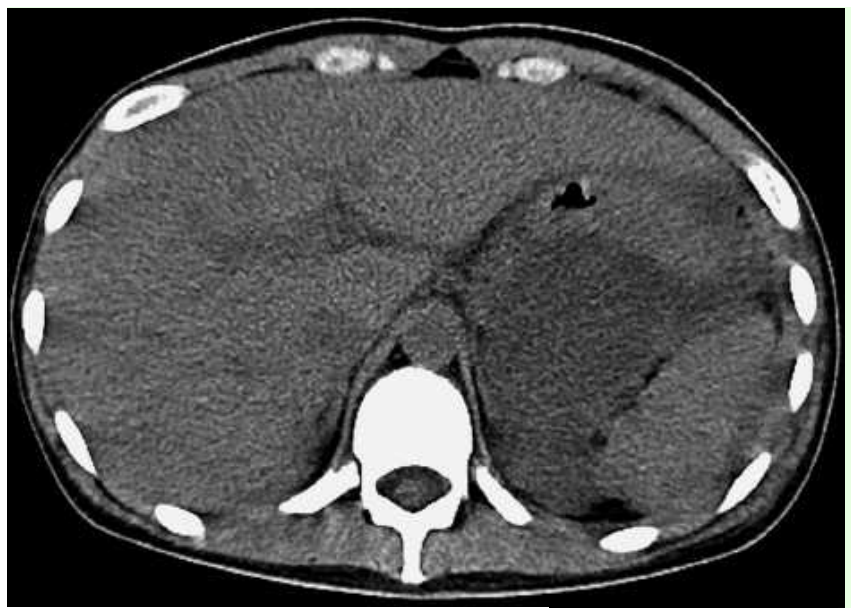

Fig. 1 Computed tomography showed a 5-cm omental bursa abscess adjacent to the stomach.

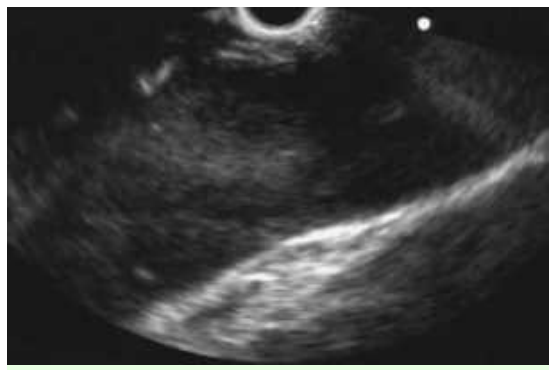

Fig. 2 Endoscopic ultrasound view of the omental bursa abscess.

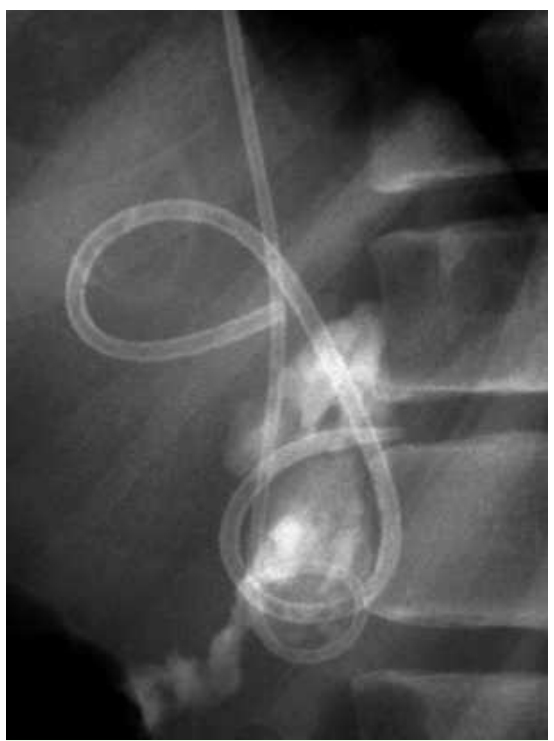

Fig. 37 Fr naso-abscess Teflon catheter and a 5-cm-long $10 \mathrm{Fr}$ double pigtail Teflon stent was successfully inserted into the abscess cavity.
Surgery is currently the mainstay of treatment for intra-abdominal abscess, although operative mortality is high [1] Percutaneous drainage is another option but is associated with significant morbidity due to the relatively long route used for catheter placement $[1,2]$. Endoscopic ultrasound (EUS)-guided drainage is potentially safe and effective for intra-abdominal abscess. We report a case of omental bursa abscess complicating appendicitis with diffuse peritonitis that was successfully and safely drained under EUS guidance.

A 28-year-old woman underwent appendectomy and surgical irrigation drainage of Pouch of Douglas, left subphrenic space, and right iliac fossa for appendicitis with diffuse peritonitis. Postoperatively after 2 weeks, the patient continued to have a high fever with elevated C-reactive protein. Computed tomography revealed a 5-cm omental bursa abscess adjacent to the stomach ( $\bullet$ Fig. 1). The decision to perform EUS-guided drainage was made to avoid further open surgery. The abscess was visualized with a curvilinear echoendoscope (GF UC 2000P, Olympus Co., Tokyo, Japan) before being punctured with a 19-gauge Echotip Ultra needle (Cook Endoscopy, Winston-Salem, North Carolina, USA) ( Fig. 2). A 480-cm-long, 0.035 -inch guide wire (Cook Endoscopy) was inserted into the abscess before the needle was removed, followed by placement of a 7 Fr naso-abscess Teflon cathe- ter (Cook Endoscopy). A 5-cm-long $10 \mathrm{Fr}$ double pigtail Teflon stent (Cook Endoscopy) was also inserted adjacent to the naso-abscess catheter to enable irrigation ( Fig.3). There were no procedurerelated complications. The catheter was removed after 1 week, when purulent material had ceased to drain from the catheter. The stent was removed 4 weeks later when CT showed complete abscess resolution. The patient was asymptomatic without any evidence of abscess recurrence at 2 months follow-up.

EUS-guided drainage of omental bursa abscess complicating appendicitis with diffuse peritonitis is safe and effective and could be an alternative therapy to surgery and percutaneous drainage.

Endoscopy_UCTN_Code_TTT_1AS_2AC

\section{H. Imazu ${ }^{1}$, Y. Kawahara ${ }^{1}$, S. Koyama ${ }^{1}$, H. Tajiri ${ }^{2}$ \\ Department of Endoscopy, The jikei University School of Medicine, Tokyo, Japan \\ Division of Hepatogastroenterology, Department of Internal Medicine, The jikei University School of Medicine, Tokyo, Japan}

\section{References}

1 Bufalari A, Giustozzi G, Moggi L. Postoperative intraabdominal abscesses: percutaneous versus surgical treatment. Acta Chir Belg 1996; 96: 197-200

2 Mueller PR, Simeone JF, Butch RJ et al. Percutaneous drainage of subphrenic abscess: a review of 62 patients. Am J Roentgenol 1986; 147: 1237 - 1240

Bibliography

DOI $10.1055 / \mathrm{s}-2008-1077683$

Endoscopy 2008; 40: E249

(c) Georg Thieme Verlag KG Stuttgart · New York . ISSN 0013-726X

\section{Corresponding author}

\section{H. Imazu, MD}

Department of Endoscopy

Jikei University School of Medicine

3-25-8 Nishi-shinbashi

Minatoku

Tokyo

Japan 105-8461

Fax: +81-3-34594524

himazu21@aol.com 